\title{
MENUJU MODERNISASI PENDIDIKAN ISLAM
}

\author{
Hartono* \\ hartono4alazhar@gmail.com \\ *Dosen Magister Pendidikan Agama Islam, Universitas Muhammadiyah Tangerang
}

\begin{abstract}
This study wass a theoretical basis for the analysis of modernization carried out by the world of Islamic education, especially in Indonesia. For this purpose, the study was distributed into three sub-chapters. The first sub-chapter discussed a historical review of the modernization of Islamic education. The second discussed the modernization of Islamic education in Indonesia. The last discussion was directed at disclosing the response of Muslims to modern education.
\end{abstract}

Keywords: Modernity, Modernism and Modernization.

\section{A. PENDAHULUAN}

Kajian ini berusaha menunjukkan adanya sekolah Islam unggul yang memiliki semangat ideologi sehingga membangkitkan pengembangan modernisasi pendidikan Islam.

Dalam dua atau tiga dekade terakhir,ideologi-ideologi yang merupakan sistem faham hidup ${ }^{1}$ yang berbentuk klasik seperti kapitalisme, sosialisme dan nasionalisme mulai kehilangan momentumnya, disusul dan diganti dengan ideologi kontemporer seperti feminisme, pluralisme dan postmodernisme. Khusus dibidang pendidikan juga diramaikan dengan ideologi-ideologi baru yang menawarkan doktrin pendidikan sebagai terapi atas krisis yang melanda dunia pendidikan.Disatu sisi hadirnya ideologi yang dibangun secara sistematis ${ }^{2}$ tersebut

1 Qadir jaelani,A, Perjuangan Ideologi Islam di Indonesia, Jakarta, Pedoman Ilmu Jaya, 1996,h. 5

Qadir jaelani,A, h. 5-6 . Pandanga tersebut untuk membahas naskah Dawam Rahardjo tentang masalah tujuan perjuangan politik umat Islam di Indonesia mengajukan pengertian tentang ideology ini dengan rumusan V.Afanasyif dalam bukunya Marxist philosophy 9 Moscow, $2^{\text {nd }}$, ed.1963dengan menyatakan : Social consciousness memperkaya pemikiran pendidikan, tetapi disisi lain dapat membingungkan para perencana dan praktisi pendidikan.

Berdasarkan pemetaan William O'Neil ada dua aliran ideologi besar yang berpengaruh, dengan varian-varian masingmasing yaitu pertama Ideologi konservatif dengan variasi: fundamentalisme, intelektualisme dan konservatisme. Kedua, Ideologi Liberal dengan variasi : liberalisme, liberasionisme dan anarkisme. ${ }^{3}$ Sebelumnya Henry Giroux juga memetakan aliran ideologi dengan agak sederhana yaitu aliran konservatisme, liberalisme dan aliran kritis. ${ }^{4}$

\section{B. PEMBAHASAN}

is the spiritual life of people, the ideas, theories and view, social sentimenthabits and custom of people which reflect objectife reality human society and nature. The sum total of political,legal, moral, artificand other views and ideas of definite class comprise its ideology.

${ }^{3}$ William F.O'Neil , Ideologi-ideologi Pendidikan,Alih Bahasa Omi IntanNaomi, Yogyakarta, Pustaka Pelajar, 2002, h. 104-120.

${ }^{4}$ Giroux H.A,Ideology, Culture and the Processof Schooling, Philadelphia : Temple University and Falmer Press, 1981

Tadarus Tarbawy. Vol. 1 No. 1 Jan-Jun 2019. 
Pembahasan modernisasi pendidikan disajikan sebagai dasar untuk memahami bentuk-bentuk pembaharuan yang dilakukan oleh dunia Islam. Terkhusus diambil sampel dari dua negeri yang penduduknya mayoritas muslim yaitu: Arab Saudi dan Mesir. Selanjutnya modernisasi pendidikan Islam di Indonesia dibahas sebagai kasus yang mewakili kawasan di Asia Tenggara. Terakhir, pengungkapan sikap umat Islam terhadap pendidikan modern dilakukan dengan maksud menyajikan peta keragaman ekspresi mereka dalam merespon satu masalah (pembangunan) yang sama.

Sejarah modernisasi di dunia Islam dalam penelitian ini merujuk pada pengertian usaha-usaha pendidikan bangsa muslim untuk membangun kembali identitasnya setelah meraih kemerdekaan dari penjajahan bangsa Eropa. Masa itu merujuk pada era pertengahan abad ke 20 . Lebih konkritnya sejak bangsa-bangsa muslim memformulasikan sistem pemerintahannya menjadi republik. Pengertian ini tidak mengabaikan sama sekali periodeisasi sejarah modern Islam yang dirumuskan sejak awal abad ke 19 oleh peneliti lain. ${ }^{5}$ Hanya saja sebagai fakta sejarah, sistem republik yang hingga saat ini telah menjadikan pendidikan Islam terus merumuskan dirinya dengan kebutuhan masyarakat yang berubah di dalamnya.

\section{Modernisasi Pendidikan Islam}

Pembahasan modernisasi pendidikan Islam memiliki hubungan dengan istilah kunci lain berupa modernitas dan modernisme. Masing-masing istilah mewakili ekspresi makna tersendiri. Ada beberapa penulis yang telah memaknai tiaptiap istilah di atas. ${ }^{6}$ Penelitian ini memaknainya sebagai berikut: Modernitas

\footnotetext{
${ }^{5}$ Lihat Badri Yatim, Sejarah Peradaban Islam, Jakarta: Rajawali Pers, cet. 16, 2004, hal. 6.

6 Lihat Nurcholish Madjid. Islam Kemodernan dan Keindonesian, Bandung: Mizan, cet. 11. 1998. Bandingkan dengan H. A. R. Tilaar, Manifesto Pendidikan Nasional Tinjauan dari Perspekti Posmodernisme dan Studi Kultural, Jakarta: Kompas. 2005. hal. 7-15.
}

merujuk pada berbagai perkembangan terbaru, baik yang bersifat matrial maupun abstrak sebagai hasil pikiran manusia untuk mengendalikan tantangan lingkungannya. Penggunaan hand phone (HP), agunan tunai mandiri (ATM) sampai kehadiran sekolah internasional adalah bentuk formal dari modernitas. Modernisme lebih merujuk pada objek yang sifatnya abstrak dan mewakili satu suasana intelektual. Substansi modernisme berada pada sikap menghargai waktu dan mandirisasi akal manusia untuk menghadapi kehidupannya dari berbagai ketergantungan terhadap alam, budaya dan dogma. Adapun modernisasi merujuk pada pengertian kerja atau proses merasionalkan, mensistematiskan dan mengendalikan realitas sosial dan alam agar sesuai dengan kebutuhan manusia. Sehingga komunitas atau masyarakat yang memfungsikan tiga makna istilah di atas disebut juga masyarakat modern.

Makna modernisasi merupakan fikiran, aliran, gerakan dan usaha untuk mengubah faham-faham, adat istiadat, institusi-institusi lama dan sebagainya untuk disesuaikan dengan suasana baru yang ditimbulkan oleh kemajuan ilmu pengetahuan dan tehnologi moderen. ${ }^{7}$

Kemajuan ilmu pengetahuan dan tehnologi moderen memasuki dunia Islam, terutama sesudah pembukaan abad ke 19 M, yang dalam sejarah Islam dipandang sebagai permulaan periode Moderen. Kontak dengan dunia Barat selanjutnya membawa ide-ide baru ke dunia Islam seperti rasionalisme, nasionalisme, demokrasi dan sebagainya.

Modernisasi atau pembaharuan dapat diartikan dengan apa saja yang belum difahami, diterima atau dilaksanakan oleh penerima pembaruan, meskipun bukan hal baru bagi orang lain. ${ }^{8}$ Pembaruan biasanya dipergunakan sebagai proses perubahan

7 Harun Nasution, Pembaharuan dalam Islam Sejarah Pemikiran dan Gerakan, Jakarta: Bulan Bintang, 1975,h.3.

${ }^{8}$ Cece Wijaya, Upaya pembaruan dalam Pendidikan dan Pengajaran, Bandung : PT. Remaja Rosdakarya, 1992,h.6 
untuk memperbaiki keadaan yang ada sebelumnya ke cara atau situasi dan kondisi yang lebih baik dari sebelumnya. ${ }^{9}$ Dengan kata lain, pembaruan sesungguhnya lebih merupakan upaya atau usaha perbaikan keadaan, baik dari segi cara, konsep dan serangkaian metode yang bisa diterapkan dalam rangka mengantarkan keadaan yang lebih baik.

Adapun pengertian modernisasi menurut Nurcholish Madjid ialah pengertian yang identik atau hampir identik dengan pengertian rasionalisasi. Dan itu berarti proses perombakan pola berfikir dan tata kerja lama yang tidak akliah(rasional) dan menggantikannya dengan pola berfikir dan tata kerja baru yang akliah. Kegunaannya ialah untuk memperoleh daya guna dan efisiensi yang maksimal. Hal itu dilakukan dengan menggunakan penemuan mutakhir manusia dibidang ilmu pengetahuan. ${ }^{10}$

Modernisasi atau pembaharuan bisa pula disebut dengan reformasi, yaitu membentuk kembali atau mengadakan perubahan yang lebih baik dapat pula diartikan dengan perbaikan. Dalam bahasa arab sering diartikan dengan Tajdid yaitu memperbaharui, sedang pelakunya disebut Mujaddid atau orang yang melakukan pembaharuan. ${ }^{11}$

Merujuk dari beberapa pengertian di atas, nampaknya terdapat beberapa bagian yang menjadi ciri suatu kegiatan dikatakan sebagai pembaruan, antara lain: pertama : mengarah kepada upaya perbaikan secara simultan. Kedua : meniscayakan pengaruh yang kuat adanya ilmu pengetahuan dan tehnologi. Ketiga : dilakukan secara dinamis, inovatif dan progresif sejalan dengan perubahan pola berfikir seseorang.

Arnold Toynbee mengatakan bahwa modernitas telah mulai menjelang akhir abad ke 15 Masehi, ketika orang Barat

${ }^{9}$ Abdul Rahman Saleh, Konsepsi dan Pengantar Dasar Pembaruan Pendidikan Islam, Jakarta : DPP GUPPI, 1993,h.8

${ }^{10}$ Nurcholish Madjid, Islam Kemoderenan dan Keindonesiaan, Jakarta: Mizan.h. 172

$\begin{array}{ccr}11 \text { Rifyal Ka'bah, } & \text { Islam } \begin{array}{r}\text { dan } \\ \text { Fundamentalisme, }\end{array} \text { Jakarta: } & \text { Pustaka }\end{array}$

berterima kasih tidak kepada Tuhan tetapi kepada dirinya sendiri atas keberhasilannya mengatasi kungkungan Kristen abad pertengahan. ${ }^{12}$ Menurut Arkoun istilah modernitas -berasal dari bahasa Latin modernus- pertama kali di pakai di dunia Kristen pada masa antar tahun 490 dan 500 yang menunjukkan perpindahan dari masa Romawi lama ke periode Masehi. ${ }^{13}$

Latarbelakang muncul pembaharuan disebabkan karena kemunduran umat Islam pada abad kesepuluh yang berupa :

Pertama, isu pintu ijtihad telah tertutup meluas di kalangan umat Islam, berpalingnya fikiran untuk menggali secara langsung pada sumber yang pertama dan utama ( Al-Qur'an dan Hadits ) apabila menemukan persoalan baru, fikiran hanya dipusatkan untuk kepentingan madzhab. ${ }^{14}$

Kedua, Keutuhan umat Islam bidang politik mulai pecah, kekuasaan kholifah menurun, pemikiran akan adanya masyarakat Islam yang berbentuk persatuan dan kesatuan dalam seiman telah pindah. $^{15}$

Ketiga, adanya perang salib dibawah arahan gereja Katolik Roma dan serbuan tentara Barbar dibawah pimpinan Khulagu Khan dari Tartar. ${ }^{16}$ Masa kemunduran ini berlangsung berabad-abad lamanya hingga muncul gerakan pemikiran yang dikumandangkan oleh pelopor-pelopor pembaharuan, seperti Ibnu Taimiyah dengan muridnya Ibnu Qayim, Muhammad Ibn Abdil wahab, Muhammad Ibn Ali Sanusi Al-Kabir dan lain-lain.

Problem yang ditimbulkan oleh modernitas di lingkungan kaum muslim semakin terasa berat karena adanya tekanan

12 Arnold Toynbee, A Study of History, diringkaskan oleh D.D.Somervelle,Oxford: Oxford University Press, 1957,j,2. h. 148.

${ }^{13}$ Arkoun, Al-Fikr Al-Islam, Naqd Wa AlIjtihad, Terj.Hasyim Shalih, Beirut: DarSaqi,Cet.II,1992,h.53.

${ }^{14}$ Edward Mortimer, Faith and Power the Politics of Islam. Terjemahan Enna Hadidan Rahmani astuti , Bandung: Mizan,1984,h.51

${ }^{15}$ Muhammad Al-Bahy, Al-Fikhu Al-Islam fi Tathawwurihi. Terjemahan Bambang Saiful Ma'arif, Bandung, 1985,h.51.

${ }^{16}$ Muhammad Al-Bahy, Al-Fikhu Al-Isrtian lami fi Tathawwurihi, h. 53

Tadarus Tarbawy. Vol. 1 No. 1 Jan-Jun 2019. 
demografis yang menimpa masyarakat Islam sejak tahun 1950 an yang bandingannya dalam sejarah dunia : despotisme lembaga politik dan ekses ideologi luar - seperti liberalisme, sekulerisme, komunisme dan sebagainya.

Dalam konteks batasan, problem dan tantangan modernitas dapat dirujuk uraian para ahli seperti Harvey Cox atau Lucian W.Pye. Paling tidak, jika merujuk pada kedua ahli itu setidak-tidaknya ada tiga pilar yang menjadi soko guru modernitas: a) Ilmu pengetahuan yang berujung pada rasionalisme. b) Negara-bangsa yang bermuara kepada nasionalisme, c) 'penyepelean' peran agama yang berujung kepada sekulerisme.Ketiga masalah inilah yang menjadi problem sekaligus tantangan bagi kaum muslim menyambut datangnya modernitas ke dunia Islam sejak abad ke 19. Namun disamping itu juga masih ada sejumlah problem turunan lainnya, seperti problem demokrasi, hak asasi manusia (HAM), toleransi, status wanita dan sebagainya.

Dengan demikian, kalau dikaitkan dengan pembaruan pendidikan Islam akan memberi pengertian sebagai suatu upaya melakukan proses perubahan kurikulum, cara, metodologi, situasi dan kondisi pendidikan Islam dari yang tradisional ke arah yang lebih rasional sejalan dengan perkembangan ilmu pengetahuan dan tehnologi.

Menurut Azra, pendidikan harus diperbaharui atau dimodernisasi sehingga dapat memenuhi harapan dan fungsi yang dipikulkan kepadanya, karena sering dianggap sebagai objek modernisasi. Dalam kontek ini, pendidikan di Negara-negara yang tengah menjalankan program modernisasi pada umumnya dipandang masih terbelakang dalam beberapa hal, dan karena itu sulit diharapkan bisa memenuhi dan mendukung program modernisasi. ${ }^{17}$

Pendidikan pada masyarakat moderen atau masyarakat yang tengah bergerak ke arah moderen pada dasarnya berfungsi

17 Azyumardi Azra, Pendidikan Islam Trsdisidan Modernisasi, h. 32. untuk memberikan kaitan antara anak didik dan lingkungan sosio kulturalnya yang terus berubah. Dalam banyak hal pendidikan secara sadar digunakan sebagai instrumen untuk perubahan dalam sistem politik dan ekonomi.

Seperti yang disimpulkan Shipman, fungsi pokok pendidikan dalam masyarakat moderen terdiri dari tiga bagian: sosialisasi, penyekolahan (schooling) dan Pendidikan (education). Sebagai lembaga sosialisasi, pendidikan adalah wahana bagi integrasi anak didik ke dalam nilai-nilai kelompok atau nasional yang dominan. Adapun penyekolahan mempersiapkan mereka untuk menduduki posisi sosial ekonomi tertentu dan karena itu, penyekolahan membekali anak didik dengan kualifikasi dan profesi yang akan membuat mereka mampu memainkan peran dalam masyarakat. Kemudian dalam fungsi yang ketiga pendidikan merupakan fungsi education yang menciptakan kelompok elit yang pada gilirannya akan memberikan sumbangan besar bagi kelanjutan program modernisasi. ${ }^{18}$

Untuk mencapai tujuan ini, pendidikan dalam proses modernisasi akan mengalami perubahan fungsional dan antar sistem. Perubahan-perubahan tersebut pada konseptual dapat dirumuskan dengan menggunakan pendekatan sistem-sistem. Don Adam yang menggunakan pendekatan sistem-sistem dalam kajian pendidikan dan modernisasi pendidikan Islam dalam kontek Indonesia secara keseluruhan. Input dari masyarakat ke dalam sistem pendidikan terdiri dari Ideologi normatif, mobilisasi politik, mobilisasi ekonomi, mobilisasi sosial dan mobilisasi kultural. ${ }^{19}$ Pada kesempatan yang sama variabel-variabel yang tercakup dalam transformasi sistem pendidikan yaitu modernisasi administratif, differensial struktural dan ekspansi kapasitas. $^{20}$

18 Shipman, M.D, Education and Modernization, London: Faber, 1972,h. 33-35.

Don Adam, Education and Modernization ,Reading Mass: Addison -Wesley Publishing Co \& Pittsburg University, 1970.

Azyumardi Azra, Pendidikan Islam,Tradisi dan Modernisasi,h.34.

Tadarus Tarbawy. Vol. 1 No. 1 Jan-Jun 2019. 
Transformasi

mempertimbangkan semua variabel tersebut, maka akan menghasilkan output pendidikan yang merupakan input bagi masyarakat yaitu perubahan sistem nilai, output politik, output ekonomi, output sosial, dan output kultural. ${ }^{21}$

Pada kasus dunia pendidikan Islam, modernisasi merupakan usaha serius umat Islam agar proses pembangunan yang mereka lakukan dapat tetap mewakili gaya hidup (way of life) Islam. ${ }^{22}$ Pendidikan Islam terus memformulasikan diri agar para pengguna layanannya yang tidak lain adalah generasi muda Islam dapat tetap berpartisipasi dengan kebutuhan masyarakatnya dan menjadi subjek yang mandiri dalam menjalani proses sejarah kemanusiaan. Kebutuhan masyarakat muslim yang dimaksud adalah ketersediaan tenaga terampil maupun ahli yang dipersyaratkan guna mengisi sektor-sektor kerja pembangunan nasional. Ada pun sejarah kemanusiaan yang dimaksud merujuk pada transformasi masyarakat dunia yang oleh Toffler saat ini dipandang telah memasuki gelombang ketiga, masyarakat informasi. ${ }^{23}$ Oleh karenanya transformasi pendidikan Islam melalui modernisasi pada prinsipnya sedang menjalankan makna dari rasionalisasi dan berorientasi kepada masa depan yang lebih baik.

Modernisasi pendidikan Islam juga dilatarbelakangi oleh kondisi internal Islam yang tidak lagi menganggap ilmu pengetahuan sebagai satu kesatuan ilmu yang harus diperhatikan. Sehingga pada proses selanjutnya ilmu pengetahuan lebih banyak diadopsi bahkan dimanfaatkan secara komprehensif oleh Barat yang pada

21 Azyumardi Azra, Pendidikan Islam, Tradisi dan Modernisasi,h. 36.

${ }^{22}$ Harun Nasution lebih memilih istilah pembaharuan, lihat Pembaharuan dalam Islam: Sejarah Pemikiran dan Gerakan, Jakarta: Bulan Bintang, 1988. Baginya istilah modernisasi di publik Indonesia terlalu polutif dipahami sebagai westernisasi.

${ }^{23}$ Lihat Alvin Toffler, Third Wave, New

York: William Morrow, 1980. waktu itu tidak mengenal ilmu pengetahuan. $^{24}$

Dengan adanya faktor yang menjadi sebab lahirnya pembaruan pendidikan Islam, maka Suwito mengatakan telah terjadi dua pemikiran pembaruan pendidikan Islam yaitu : 1) pola pembaruan pendidikan Islam yang berorientasi pada pola pendidikan moderen di Barat dan 2) pembaruan pendidikan Islam yang berorientasi pada tujuan pemurnian kembali ajaran Islam. $^{25}$

Persoalan modernisasi merupakan salah satu diskursus dalam sosiologi. Sebelum menjadi salah satu teori, diskusi modernitas didorong dan dipengaruhi oleh kekuatan intelektual pada Abad Pencerahan. ${ }^{26}$ Abad itu melahirkan arus intelektual utama yang ditandai dengan tradisi yang memposisikan akal secara dominan sebagai alat untuk menjelaskan dan mengendalikan lingkungan alam dan sosial guna menciptakan kesejahteraan hidup manusia baik pada level individu maupun masyarakat. Tradisi ini menandai lahirnya masyarakat baru di Barat dan disebut sebagai era modern karena sifat masyarakatnya yang rasional.

Teori sosiologi saat ini masih memperdebatkan apakah tatanan masyarakat Abad 21 masih tepat disebut modern atau telah memasuki era postmodern. Giddens dalam hal ini masih menegaskan bahwa kehidupan saat ini masih tepat dilukiskan sebagai era modern. Ia menggunakan istilah yang lebih khusus lagi bahwa saat ini merupakan kehidupan

${ }^{24}$ Suwito, Sejarah Sosial Pendidikan Islam, Jakarta: Prenada Media, 2005,h.164.

${ }^{25}$ Suwito, Sejarah Sosial Pendidikan Islam,h. 166.

${ }^{26}$ Abad pencerahan (enlightenment) adalah sebuah priode perkembangan intelektual dan pembahasan pemikiran filsafat yang luar biasa. Pemikir (filsuf) paling terkemuka pada zaman itu adalah C. Montesquieu (w. 1755) dan J.J Rousseau (w. 1778). Mereka dipengaruhi oleh filsuf modern klasik (Abad 17) seperti R. Descartes (w.1650), T. Hobbes (w. 1679) dan J. Locke (w. 1704). Lebih lanjut lihat Irving M. Zeitlin, Ideology and the Development of Sociological Theory, Englewood Cliffs- New Jersey: Prentice-Hall, 1996 (edisi $6^{\text {th }}$ ), hal. 10.

Tadarus Tarbawy. Vol. 1 No. 1 Jan-Jun 2019. 
modern tingkat tinggi atau akhir. Ia menganalogikan era modern saat ini sebagai sebuah panser raksasa (juggernaut) yang pada kondisi tertentu dapat menyebabkan dirinya hancur lebur. ${ }^{27}$ Tidak kalah tajam dengan Giddens dalam menganalisis, Beck menyebut bahwa saat ini kehidupan masih berada di era modern dalam bentuknya yang baru. Jika modernitas klasik memandang bahwa kelas sosial adalah sentral dalam masyarakat industri maka pada era modern yang baru resiko merupakan fundamen di dalamnya, bahkan keduanya (resiko dan kelas sosial) saling berhubungan. ${ }^{28}$ Modernisasi kini telah melarutkan masyarakat industri dan melahirkan tipe modernitas lain yang bahkan di luar rencana masyarakat industri klasik.

Kapitalisme dan industrialisme adalah ciri yang masih disepakati oleh teoritisi modern era klasik maupun kontemporer. ${ }^{29}$ Kedua kepentingan itu lah kemudian mempengaruhi proses pembentukan masyarakat dan regenerasinya. Untuk kepentingan regenerasi, masyarakat pada awalnya menyelenggarakan aktifitas pendidikan melalui institusi keluarga dan lingkungan. Institusi pendidikan yang semula berada di lingkungan keluarga dan masyarakat serta bersifat in dan non formal kemudian mengalami transformasi dalam bentuk sekolah serta bersifat formal. Pada saat pendidikan masih berlangsung di keluarga dan masyarakat tujuan utamanya adalah semata-mata sarana pewarisan nilai dan sosialisasi. Berbeda saat memasuki era kapitalisasi dan industrialisasi, pendidikan bertujuan menjadi lebih positifistik yaitu menyiapkan tenaga kerja terampil dan ahli guna meningkatkan produksi. Dalam

27 Lihat Anthony Giddens, The Consequences of Modernity, Stanfor- Calif: Stanford University Press, 1990, hal. 139.

${ }^{28}$ Lihat Ulrich Beck, Risk Society: Towards a New Modernity, London: Sage Pub., 1992, hal. 37.

${ }^{29}$ Lihat Lihat G. Ritzer \& D. J. Goodman, Modern Sociological Theory 6th, New York: McGraw-Hill, 2003, hal. 250. Juga lihat Karl Max, Das Kapital A Critique of Political Economy, dalam Friedrich Engels (ed.) Chicago: Henry Regnery Company, tt., hal. 240-246. konteks ini maka pendidikan direduksi menjadi sistem persekolahan dan fungsi utamanya adalah sebagai instrumen dalam proses produksi.

Saat bangsa-bangsa muslim terbebas dari kolonialisasi bangsa Eropa, mereka dihadapkan masalah yang hampir seragam. Mereka melaksanakan struktur kepemimpinan baru yang tidak lagi berbentuk kerajaan, kesultanan dan dinasti sebagaimana yang telah diwariskan oleh sejarah Islam sejak era Muawiyah. ${ }^{30}$ Kalau pun hingga saat ini masih ada; Kerajaan Brunei di Asia Tenggara maupun Kerajaan Saudi di kawasan Arab, maka hal itu tidak menjadi arus utama perubahan bangsa muslim yang berada di kawasan yang lain. Sistem republik memposisikan rakyat sebagai pemegang kedaulatan dan merupakan pejungkirbalikan sistem kerajaan.

Selain bersistem republik, bangsabangsa muslim juga dihadapkan pada masalah pertumbuhan penduduk yang besar dengan tingkat pendidikan yang rendah untuk membangun negara bangsa. Kondisi itu menjadi problem sosial tersendiri karena menuntut pemerintah baru membuka seluas-luasnya akses lapangan kerja dan layanan pendidikan yang berkualitas. Masalah itu semakin membebani pemerintahan baru mereka dikarenakan dukungan dana yang terbatas bahkan mendapat warisan hutang dari bangsa penjajahnya. ${ }^{31}$ Realitas yang kompleks ini menjadi kenyataan yang meliputi keberadaan pendidikan Islam. Sayangnya, hampir di setiap negeri muslim yang terbebas dari penjajahan itu mengambil jalan pintas penyelesaian dengan

${ }^{30}$ Penelitian komprehensif tentang sejarah dinasti, kerajaan dan kesultan dalam sejarah Islam lihat Ira. M. Lapindus, A History of Islamic Societies, dalam Ghufron A. Mas'adi (penerjemah) menjadi Sejarah Sosial Ummat Islam, Jakarta: Rajawali Pers, cet. 2, 2000.

31 Sepeninggal Belanda, Indonesia mendapat warisan hutang sebesar 4 Miliar Dolar AS. Lihat Sri Hartati Samhadi, Bermimpin Indonesia Merdeka dari Hutang, dalam Opini Kompas, http://www.kompas.com/kompascetak/0605/20/sorotan/2659164.html. 
melanjutkan dan memassalkan sistem pendidikan yang pernah dikelola oleh Bangsa penjajah dan membiarkan pendidikan Islam di lain pihak. Dampaknya selain melahirkan dualisme sistem pendidikan, pengabaian keberadaan lembaga pendidikan Islam telah berhasil mengancam keberlangsungan gaya hidup Islam (way of life) dalam masyarakat Islam sendiri. Baru pertama kali dalam sejarah Islam muncul konflik dalam hubungan Islam dan masyarakatnya sendiri.

Berada pada kondisi tersebut, kelas terdidik Islam merasakan masalah besar akan muncul apabila keputusan jalan pintas di atas tidak diimbangi dengan penguatan sistem pendidikan Islam. Kebijakan dan kebajikan lama yang menempatkan orientasi tafaqahu fiddin pada sendi utama pendidikan Islam mulai mendapatkan peninjauan kembali. Menindaklanjuti itu munculah eksperimen-eksperimen di kalangan elit dan kelas menengah muslim terdidik. Mereka utamanya yang memiliki pengalaman dan akses pendidikan terhadap sistem pendidikan penjajah dan buah dari belajar ke luar negeri.

Dunia pendidikan Islam klasik belum sama sekali mengenal tujuan-tujuan positifistik sebagaimana sistem pendidikan dalam masyarakat modern-industrialistis. Namun demikian watak modern yang diidentikan dengan sikap rasional dan demokratis bukan berarti tidak ada dalam budaya bangsa-bangsa muslim. Keberadaan paham keagamaan Mu'tazilah yang berkembang pada masa Dinasti Abasiyah adalah salah satu bukti historis watak rasionalisme dalam sejarah Islam. ${ }^{32}$ Bahkan karakteristik masyarakat demokratis dalam Islam juga dapat diidentifikasi pada masa kepemimpinan Nabi Muhammad dan empat khalifah yang digelari rasyidin. ${ }^{33}$ Oleh karenanya meskipun pendidikan Islam dihadapkan pada pekerjaan sejarah yang

${ }^{32}$ Lihat Harun Nasution, Islam Ditinjau dari Berbagai Aspeknya, Jakarta: UI Press, 1985.

${ }^{33}$ Hal demikian karena proses pergantian pemimpin tidak menggunakan garis keturunan. Lebih lanjut lihat R. N. Bellah, Beyond Belief Essays on Religion in a Post- Traditional Word, Berkeley: University of California Press, 1991, hal. 150-151. panjang (agar bangsa-bangsa muslim menjadi negara maju) paling tidak mereka tidak memulai dari nol sama sekali.

Sebagai bagian proses sejarah, modernisasi pendidikan Islam mulai mengintrodusir tujuan-tujuan pragmatis ke dalam sistemnya. Sebagai bahan perbandingan, modernisasi pendidikan Islam di berbagai bangsa muslim memiliki beberapa bentuk eksperimen. Berikut dideskripsikan beberapa eksperimen itu di Mesir, dan Saudi. Pemilihan ini didasarkan pada kawasan yang punya pengaruh kuat terhadap modernisasi pendidikan Islam di Indonesia.

Modernisasi pendidikan Islam di Mesir awal mula diarsiteki langsung oleh pemerintah Muhammad Ali Pasha (18051848). Proyek modernisasi pendidikan di Mesir pertama kali memilih dunia militer sebagai bidang garapnya. Pada masa itu universitas Al-Azhar masih fokus menyelenggarakan studi Islam, namun demikian dari Al-Azhar lah proses rekrutmen dilakukan untuk mengisi sekolah-sekolah militer dan administrasi. Memasuki Abad ke 20 modernisasi pendidikan Islam di Mesir mulai memasuki jenjang pendidikan dasar. Kurikulum pokok di dalamnya terdiri dari materi agama, berhitung, dan bahasa (membaca dan menulis).

Sepulang studi dari negeri-negeri Eropa, kelas muslim terdidik Mesir terdorong untuk menciptakan sistem pendidikan yang mampu mengakomodasi tatanan sosial, ekonomi, politik negara modern. Sebuah sistem pendidikan yang tidak semata-mata mewariskan ilmu kepada generasi baru Mesir namun juga mampu membekali peserta didik kesadaran akan konteks sosial-politik dari setiap produk ilmu yang dikonsumsi. Italia, Perancis dan Inggris merupakan beberapa negara tempat kelas terdidik itu menemukan kesadaran baru tentang sisi lain dunia pendidikan. Atas dukungan negara, pengiriman para sarjana ketiga negara di atas berjalan. Pada tahun 1809-1819, Muhammad Ali mengirimkan para sarjana Mesir ke Italia untuk mempelajari ilmu di bidang militer, 
percetakan, teknik dan perkapalan. Pada tahun 1820 pengiriman beralih ke Perancis sampai era 1880an. Setelah itu baru pengiriman diarahkan ke Inggris dengan fokus studi bidang-bidang sosial humaniora.

Pada konteks kebijakan internal, Muhammad Ali pada era 1816 membuka sekolah ala Barat yang di dalamnya mempelajari bidang kemiliteran, aritmatika dan teknik-teknik yang berkembang di Italia. Rekrutmen secara massif dilakukan Muhammad Ali mulai dari jenjang pendidikan dasar militer. Program ini terus berlangsung dan ditindak lanjuti dengan membuka sekolah-sekolah kedokteran, pertanian, farmasi dan kedokteran hewan. ${ }^{34}$ Yang unik dari itu semua, Muhammad Ali mengkontrol seluruh kegiatan itu di bawah pengawasan departemen militer. Suatu pandangan dan tindakan yang bisa dikategorikan brilian-realistis. Negara yang kuat dalam catatan sejarah kemanusiaan tidak cukup memimiliki kebudayaan yang tinggi namun perlu juga didukung oleh kekuatan militer yang besar. Amerika (AS) adalah contoh paling konkrit pada abad ini. Selain pusat perkembangan ilmu pengetahuan, AS juga terus memperkuat inovasi persenjataan militernya untuk mengamankan tatanan dunia.

Selain pendidikan dasar kemiliteran dibuka, Muhammad Ali tidak melewatkan perhatian untuk memberdayakan publik Mesir. Program pendidikan dasar yang memadukan pengetahuan agama dan sains digulirkan kepada mereka. Lembaga pendidikan ini merekrut generasi Mesir yang berusia 7 sampai dengan 12 tahun. Kebijakan ini disatu sisi akhirnya juga tidak menjadikan kuttab (lembaga pendidikan tradisional Islam di Mesir) sebagai titik tolak modernisasi pendidikan Mesir. Namun demikian hanya aspek keagaaman saja yang diadobsi kedalam sistem pendidikan ala Barat yang diinisiasi oleh Muhammad Ali. Pada saat cucu Muhammad Ali (Khadive Ismail)

34 Lihat M. Winter, Educational Development under Muhammad Ali, EI CD-Rom Edition, Vol. 11, 2001. mengambil tongkat estapet kepemimpinan, baru transformasi terhadap kuttab dilaksanakan. Transformasi itu dilakukan dengan menambahkan mata pelajaran sains sosial dan alam ke dalam struktur kurikulum kuttab. Pada masa Ismail itu lah baru dinas kependidikan yang semula menginduk ke departemen militer diindependenkan menjadi departemen tersendiri dengan dukungan pembiayaan dari dana wakaf.

Pasca Mesir meraih kemerdekaan, sistem pendidikannya kembali membenahi diri. Pendidikan dasar dibuka dengan lama belajar selama lima tahun. Pada tingkat menengah dilaksanakan selama 4 tahun dan jenjang atas selama 2 tahun. Sistem ini mirip dengan sistem pendidikan yang diberlakukan oleh negara-negara persemakmuran yang menggunakan standar Cambridge. Masa dua tahun pada jenjang pendidikan atas adalah persiapan menuju jenjang perguruan tinggi.

Pendidikan tinggi yang amat populer di Mesir adalah Al-Azhar. Lembaga ini termasuk yang paling belakangan mendapat sentuhan modernisasi dari pemerintah. Reformasi kelembagaan dimulai pada 1896 dengan dibentuknya Majlis Senat Al-Azhar dengan komposisi perwakilan dari empat Mazhab dan 2 orang perwakilan pemerintah. Diantara kebijakan awal yang dikeluarkan pada masa itu adalah regulasi tentang masa belajar dan kurikulum di al-Azhar. Mereka membagi masa belajar di Al-Azhar menjadi 2 periode, yaitu pendidikan dasar 8 tahun dan pendidikan menengah-tinggi 12 tahun. Dari segi kurikulum, periode 1872-1936 masih memperlihatkan kajian keislaman terlalu dominan di dalamnya. Bahkan Materi-materi pokok pada pendidikan dasar dan menengah terdiri dari ilmu klasik Islam dan Bahasa Arab termasuk dalam hal keberadaan fakultas yang tersedia di AlAzhar, masih agama semata. Baru pada priode (1958-1964), terjadi modernisasi besar-besaran di bawah kepemimpinan Mahmud Syalthout. Saat ini bahkan AlAzhar telah memiliki 50 fakultas lengkap agama dan umum yang tersebar di seluruh provinsi Mesir. 
Berbeda dengan kawasan di atas, modernisasi pendidikan di Kerajaan Arab Saudi punya formatnya tersendiri. Kawasan ini merupakan salah satu pusat studi Islam bagi bangsa-bangsa muslim. Sejak diproklamasikan pada 23 September 1932, kerajaan Saudi menjadi pengendali politik dan agama di tanah tempat kelahiran Nabi Muhammad. Tidak ingin tertinggal dengan perkembangan terbaru dalam dunia sains alam dan teknologi, pada tahun 2007 Kerajaan Saudi mendirikan Univeritas Sains dan Teknologi Raja Abdullah. ${ }^{35}$ Raja Abdullah menanam modal 12,5 miliar Dollar untuk perguruan tinggi ini. Kampus KAUST ditempatkan di lahan seluas $36 \mathrm{~km}$ persegi dan dilengkapi dengan laboratorium tercanggih dunia, yang akan menjadi pusat penelitian para dosen dan ilmuwan terkemuka dunia. Dua pertiga dari 2000 bangku kuliah diperuntukkan bagi para mahasiswa internasional.

KAUST berobsesi menjadi perguruan tinggi terkemuka yang berorientasi pada penelitian. Panutan KAUST antara lain adalah Massachusetts Institute of Technology (MIT) atau Institut Teknologi Massachusetts di Amerika Serikat. KAUST bermitra dengan perguruan tinggi top dunia seperti Berkeley, Cambridge, Stanford, Imperial College London dan Universitas Teknik München. Universitas-universitas itu menerima dana jutaan Dollar agar melakukan penelitian di KAUST. ${ }^{36}$ Titik perhatiannya adalah biologi, teknologi nano, teknik energi, teknik material dan informatika. Universitas Teknik München menerima dana 21 juta Dollar untuk tiga proyek penelitiannya. Salah satunya adalah proyeksi tiga dimensi Arab Saudi, yang tidak hanya menggambarkan permukaan tanahnya, melainkan juga struktur geologi bawah tanahnya.

Kini Arab Saudi mulai melangkah menjadi bangsa ilmu pengetahuan. Padahal

${ }^{35}$ Dalam bahasa Inggris perguruan tinggi itu bernama King Abdullah University Science and Tecnology (KAUST).

${ }^{36}$ Lihat Lucky Setyarini dalam http://id.qantara.de/webcom/show_article.php/_c769/_nr-37/i.html, Publikasi 13 Oktober 2009, pukul: 15:08 WIB.
Arab Saudi dikenal sebagai negara yang penuh larangan terhadap apa yang disebut pemikiran bebas. Arab Saudi juga dikenal menduduki peringkat ilmu pengetahuan yang terendah dan sistem pendidikannya dikenal sebagai salah satu yang terburuk di dunia. Arab Saudi juga dikenal sebagai negara di mana ulama dan polisi syariahnya sangat berkuasa dengan dominasi paham keagamaan fersi Imam Hambali. ${ }^{37}$ KAUST mewakili simbol baru atas nilai kebebasan di kawasan Arab. Di kampus itu laki-laki dan perempuan mendapatkan kesempatan yang sama mengakses pendidikan dan melakukan penelitian. Di dalam lokasi KAUST, perempuan bahkan diperbolehkan menyetir mobil. Bagi Arab Saudi, KAUST memiliki nilai simbolis yang sangat tinggi, lebih tinggi dari nilai keilmuannya.

Tidak berhenti sampai KAUST, Raja Abdullah juga pada tahun 2008 mendirikan pembangunan universitas pertama satusatunya untuk wanita di Negara Arab Saudi. Universitas yang lebih dikenal dengan Princess Noura Bin Abdelrahman University for Girls itu memberikan kuliah di bidang kedokteran, farmasi, manajemen, ilmu komputer dan bahasa yang wanita menemukan kesulitan di universitas biasa tempat pemisahan gender yang keras diberlakukan. ${ }^{38}$ Awalnya hal demikian merupakan susutu yang kurang lazim di Negara itu karena Otoritas keagamaan yang sangat berkuasa di Arab Saudi pada masa lalu telah menentang upaya untuk memperluas pendidikan bagi wanita dan menempatkan mereka di tempat kerja, tapi Raja Abdullah sejak memimpin tahun 2005 mendorong pembaruan sosial untuk menambah pekerjaan/jabatan bagi wanita di ruang publik.

Melalui dua contoh Negara muslim di atas maka dapat dipertegas bahwa tema kunci yang menjadi perdebatan didalamnya

\section{${ }^{37}$ Lihat}

http://www.antara.co.id/view/?i=1234742017\&c=IN T\&s=, Publikasi, Senin 16 Februari 2009, pukul 06:53 WIB.

${ }^{38}$ Llihat

http://www.republika.co.id/berita/10747/arab_saudi dirikan_universitas_wanita, Publikasi 30 Oktober 2008, pukul 06:52 WIB. 
merujuk pada tarik menarik antara sekulerisasi dan konservatisasi agama di balik pesan modernisasi pendidikan Islam. Pada ranah sosiologi sendiri perdebatan itu menjadi peta akademik tersendiri.

Ilmuwan klasik yang optimis terhadap masa depan manusia melalui modernisme berani berhipotesis bahwa sekularisme adalah masa depan modernisasi. Menurut Sigmund Freud (w. 1939) sebagai contoh, dia menulis buku "The Future of an Illusion" dan berpendapat bahwa ajaranajaran agama akan segera ditinggalkan oleh masyarakat modern karena ketidak rasionalannya. ${ }^{39}$ Teori ini didukung oleh Auguste Comte (w. 1857), Emile Durkheim (w. 1917), Max Weber (w. 1920) yang juga mengatakan bahwa semakin modern masyarakat maka agama akan semakin ditinggalkan. ${ }^{40}$

Sosiolog klasik lain, Auguste Comtemenerbitkan karya yang berjudul The Positive Philosophy menegaskan bahwa masa depan agama akan suram. ${ }^{41}$ Melalui karya itu ia mengenalkan teori hukum tiga tingkatan (evolusi). Teori itu menyatakan bahwa ada tiga tingkatan intelektual yang dilalui masyarakat di sepanjang sejarahnya. Pertama, tahap teologis; pada tingkatan ini sistem gagasan masyarakat menekankan pada keyakinan bahwa kekuatan adikodrati, tokoh agama dan keteladanan kemanusiaan menjadi dasar segala sesuatu. Dunia sosial dan alam fisik khususnya dipandang sebagai ciptaan Tuhan. Kedua, tahap metafisik; tingkatan ini ditandai oleh keyakinan bahwa kekuatan abstraklah yang menerangkan segala sesuatu, bukannya dewa-dewa personal. Ketiga, tahap positivistik; tingkatan ini ditandai oleh keyakinan terhadap ilmu sains. Masyarakat mulai cenderung menghentikan penelitian terhadap penyebab absolute (Tuhan dan

39 Sigmund freud, The Future of an Illusion, New York: Norton, 1961 hal. 9-10.

40 Indikator penurunan pengaruh agama dalam masyarakat modern lihat, Michael S. Northcott, Sociological Approaches, dalam Peter Canoly (ed.), Approaches to the Study of Religion, London \& New York: Cassell, 1999, hal. 214.

${ }^{41}$ Auguste Comte, The Positive Philosophy, New York: AMA Press, 1830-1842/1974. alam) dan memusatkan perhatian pada pegamatan terhadap alam fisik dan dunia sosial guna mengetahui hukum-hukum yang mengaturnya. Comte terlihat begitu percaya diri dengan teorinya dan tidak melihat fakta peradaban lain selain Barat yang juga memiliki tradisi rasional.

Kesimpulan di atas ditolak oleh pengamat sosiologi agama. Hal demikian setidaknya dapat dilihat pada karya berjudul Community, Society, Globality, and the Category of Religion yang ditulis oleh Roland Robertson. ${ }^{42}$ Melalui karya itu ia berpendapat bahwa modernisasi tidak menyebabkan kematian agama tetapi lebih memunculkan bentuk-bentuk agama baru yang lebih terindividualisasi dan bernuansa mistis yang tetap memberikan makna dan formasi identitas dalam kesadaran individu dan kelompok. Selain itu, kemunculan gerakan keagamaan dan sekte-sekte dalam skala kecil-kecil bisa diindikasikan sebagai penguatan identitas agama dalam konteks modern. ${ }^{43}$

Dikalangan cendekiawan muslim hal demikian juga menjadi argument mereka. Yusuf Qordhawi berargumen bahwa bahwa masa depan kemanusiaan akan menganut nilai-nilai ketuhanan dan Islam termasuk satu dari sekian agama yang bisa diharapkan memimpin evolusi sejarah manusia. ${ }^{44}$ Untuk teori yang ditulis oleh Auguste Comte, secara khusus Yusuf Qardhawi merespon dengan mengajukan data historis tentang masa-masa kejayaan umat Islam yang pernah mengalami puncak keilmuan dari berbagai disiplin. Pada fase itu ilmuan Islam tetap mampu memiliki keseimbangan antara kemajuan ilmu pengetahuan dan keyakinan beragama. Ibnu

${ }^{42}$ Roland Robertson, Community, society, Globality, and the category of religion, (edited by: James A. Beckford, Eileen Barker \& Bryan R. Wilson), Oxford: Claredon Press, 1993.

43 Michael S. Northcott, Sociological Approaches, dalam Peter Canoly (ed.), Approaches to the Study of Religion) London \& New York: Cassell, 1999, hal. 217.

${ }^{44}$ Yusuf Qardhawi, al-Dîn fî̀ 'Ashr al-'Ilm, Ghazali Mukri (penerjm.), Ilmu Pengetahuan dalam Perspektif Islam, Yogyakarta: Izzan Pustaka, 2003, hal. 60

Tadarus Tarbawy. Vol. 1 No. 1 Jan-Jun 2019. 
Rusyd sebagai contoh, ilmuan satu ini selain pakar di bidang filsafat Aristotelian, ia juga memiliki kepakaran dalam bidang agama dan medis. Pada bidang agama, kepakarannya dapat dilihat melalui karya yang mendapat pengakuan internasional seperti Bidayah al-Mujtahid wa Nihayat alMuqtashid dan pada bidang medis ia menulis karya berjudul al-Kulliyah .

Mencermati peta perdebatan di atas, penelitian ini berpandangan bahwa ujung modernisasi baik yang berupa sekularisasi maupun konservatisme agama bukan kesimpulan yang bersifat universal. Bukan pula kemestian historis akibat perubahan struktur dan budaya masyarakat. Ujung atau hasil dari modernisasi lebih tampak sebagai pilihan aktor pelaku modernisasi itu sendiri. Bagi masyarakat yang memiliki ekspresi batin bahwa lepasnya aturan agama dalam ruang publik membawa perbaikan kualitas hidup maka akan merasa welcome ketika ujung dari modernisasi benar-benar sekuler, begitu sebaliknya. Dua pandangan itu tidak dapat saling dipaksakan karena konsekwensinya mempersyaratkan teritori dan tanah air bagi mereka secara terpisah. Jika hal ini terlalu berat dilakukan maka dua kata yang dapat menjadi perekat di antara keduanya, yaitu kompromi dan negosiasi. Jika tidak juga mampu dilakukan maka pilihan terakhir adalah penaklukan.

\section{KESIMPULAN}

Adapun kesimpulan sementara dari pemahaman modernisasi pendidikan yaitu terdapat beberapa negara Islam yang berusaha mengejar ketertinggalannya dalam dunia pendidikan dari bangsa Eropa yang lebih maju. Mereka ikut belajar dengan bangsa Eropa dengan cara mengirim anakanak bangsa yang terbaik menimba ilmu untuk dikembangkan di dalam negerinya seperti Turki.

\section{DAFTAR PUSTAKA}

Abdul Rahman Saleh, Konsepsi dan Pengantar Dasar Pembaruan
Pendidikan Islam, Jakarta : DPP GUPPI, 1993.

Alvin Toffler, Third Wave, New York: William Morrow, 1980.

Arkoun, Al-Fikr Al-Islam, Naqd Wa AlIjtihad, Terj.Hasyim Shalih, Beirut: Dar-Saqi,Cet.II,1992.

Arnold Toynbee, A Study of History, diringkaskan oleh

D.D.Somervelle, Oxford: Oxford University Press, 1957,j,2. h. 148.

Anthony Giddens, The Consequences of Modernity, Stanfor- Calif: Stanford University Press, 1990.

Auguste Comte, The Positive Philosophy, New York: AMA Press, 18301842/1974.

Azyumardi Azra, Pendidikan Islam Trsdis idan Modernisasi.

Badri Yatim, Sejarah Peradaban Islam, Jakarta: Rajawali Pers, cet. 16, 2004.

Cece Wijaya, Upaya pembaruan dalam Pendidikan dan Pengajaran, Bandung : PT. Remaja Rosdakarya, 1992.

Don Adam, Education and Modernization, Reading Mass: Addison -Wesley Publishing Co \& Pittsburg University, 1970.

Edward Mortimer, Faith and Power the Politics of Islam. Terjemahan Enna Hadidan Rahmani astuti , Bandung: Mizan,1984.

Qadir jaelani,„A, Perjuangan Ideologi Islam di Indonesia, Jakarta, Pedoman Ilmu Jaya, 1996.

G. Ritzer \& D. J. Goodman, Modern Sociological Theory 6th, New York: McGraw-Hill, 2003.

Giroux H.A,Ideology, Culture and the Processof Schooling, Philadelphia : Temple University and Falmer Press, 1981. Harun Nasution, Pembaharuan dalam Islam Sejarah Pemikiran dan Gerakan, Jakarta: Bulan Bintang, 1975,h.3.

Harun Nasution, Pembaharuan dalam Islam Sejarah Pemikiran dan Gerakan, Jakarta: Bulan Bintang, 1975,h.3. 
Muhammad Al-Bahy, Al-Fikhu Al-Islam fi Tathawwurihi. Terjemahan Bambang Saiful Ma'arif, Bandung, 1985.

Nurcholish Madjid. Islam Kemodernan dan Keindonesian, Bandung: Mizan, cet. 11. 1998.

Rifyal Ka'bah, Islam dan Fundamentalisme, Jakarta: Pustaka Panjimas, 1984.

Roland Robertson, Community, society, Globality, and the category of religion, (edited by: James A. Beckford, Eileen Barker \& Bryan R.
Wilson), Oxford: Claredon Press, 1993.

Sigmund freud, The Future of an Illusion, New York: Norton, 1961.

Shipman, M.D, Education and Modernization , London: Faber, 1972.

Suwito, Sejarah Sosial Pendidikan Islam, Jakarta: Prenada Media, 2005.

William F.O'Neil , Ideologi-ideologi Pendidikan,Alih Bahasa Omi Intan Naomi, Yogyakarta, Pustaka Pelajar, 2002 